\title{
EJA EM PONTA GROSSA: CARACTERÍSTICAS DO PÚBLICO DISCENTE ${ }^{1}$
}

\author{
Rita de Cássia da Silva Oliveira ${ }^{2}$
}

UEPG

\section{RESUMO:}

O tema Educação de Jovens e Adultos atualmente está em efervescência no Brasil. Os estudos e pesquisas estão se intensificando e reafirmando a educação como um direito prescrito na Constituição e, o Estado e a sociedade civil devem assumir esta responsabilidade. A pesquisa buscou identificar as escolas que possuem a referida modalidade de ensino em Ponta Grossa, estabelecer o perfil dos alunos que a frequentam, relacionar os motivos que os levaram a voltar a estudar e as expectativas que possuem com relação a escolaridade. Realizou-se uma pesquisa bibliográfica e de campo, utilizando questionário para coleta de dados que foi respondido por 209 alunos da EJA em 35 escolas de Ponta Grossa.

Palavras-chave: Políticas Públicas, EJA, Educação Permanente.

\section{EJA IN PONTA GROSSA: CHARACTERISTICS OF STUDENTS}

\section{ABSTRACT:}

The theme of Youth and Adult Education is currently in turmoil in Brazil. Studies and research are increasingly recognized and reaffirmed education as a right prescribed in the Constitution and the state and civil society must shoulder this responsibility. The research sought to identify schools that have such a mode of education in Ponta Grossa, establish a profile of students who go there, list the reasons that led them to go back to school and the expectations they have regarding education. We conducted a literature search and field, using a questionnaire to gather data that was answered by 209 students in 35 schools EJA Ponta Grossa.

Keywords: Public Policy, EJA, Continuing Education.

\section{INTRODUÇÃO}

A Educação de Jovens e Adultos (EJA) configura-se com uma modalidade de ensino que se mantêm em constante conflito, pois em inúmeros quesitos (metodologia, avaliação, conteúdos, carga horária, entre outros) não se chega a um consenso. Existem recomendações próprias na LDB (9394/96) e metas para a modalidade no Plano Nacional de Educação (considerando-se o PNE 2001-2010, lei 10.172/01 e o projeto do PNE 20112020), porém apesar das disposições de tais políticas percebe-se que a prática é muito distante das mesmas.

A EJA por muitos anos foi considerada como educação compensatória, destinada para aqueles que não conseguiram frequentar por diversos motivos a escolaridade básica ou que a deixaram precocemente. Esta modalidade também recebeu muitas críticas pela formação aligeirada e insuficiente para seus alunos. 
Pode-se perceber que a EJA na sociedade brasileira tem recebido maior atenção inclusive na legislação nacional, entretanto na prática ainda é encarada com preconceito e considerada uma educação de segunda categoria.

A educação é considerada um instrumento de empoderamento pessoal e social, sendo assim, surge a preocupação de escolarizar a população, considerando o ingresso e a permanência na escola regular uma prioridade. Porém, existe uma lacuna para que esta realidade se efetive.

A pesquisa buscou identificar as escolas que possuem a referida modalidade de ensino em Ponta Grossa, estabelecer o perfil dos alunos que a freqüentam e relacionar os motivos que os levaram a voltar a estudar e as expectativas que possuem com relação a escolaridade.

A pesquisa faz parte de um Projeto intitulado "A construção sócio-histórica da EJA no Município de Ponta Grossa”, o qual recebeu auxílio da Fundação Araucária. Realizouse uma pesquisa bibliográfica e pesquisa de campo em 35 escolas de Ponta Grossa que possuem a modalidade da EJA, utilizando como instrumento de pesquisa um questionário que foi respondido pelos alunos.

\section{EDICAÇÃO DE JOVENS E ADULTOS (EJA)}

A EJA estrutura-se como uma modalidade que se apresenta como um grande desafio para a educação brasileira na tentativa de superar o analfabetismo. É possível observar a ineficácia de diversos programas e projetos relacionados à Educação de Jovens e Adultos no Brasil, tal como a quantidade de analfabetos funcionais que mesmo sendo submetidos às instituições ou programas da EJA mantêm-se desajustados, não conseguindo compreender textos simples ou até mesmo grafar o próprio nome.

As antigas práticas educativas voltadas para esta modalidade de ensino caracterizava-se pelo aligeiramento de ensino, conhecidas como "Ensino Supletivo". Durante a ditadura militar (1960-1985), a educação para jovens e adultos passou a ser entendida como um direito e ser reivindicada como um dever do Estado, crescendo em número as diferentes iniciativas para este segmento da população.

Despertou-se o interesse das Organizações Não-Governamentais, grupos populares e diversas instituições de ensino superior para educação de jovens e adultos. "As universidades, principalmente as públicas, vem assumindo, ainda que lentamente, seu papel na formação do docente para atuar na EJA e na produção de conhecimento na área" (SOARES, 2002, p. 8).

Entretanto, o que preocupa é o fato de não existir uma política educacional voltada para atender às expectativas e necessidades de toda essa população. É a grande mão-deobra que está voltada para a produção, constituindo-se na classe dos marginalizados, analfabetos ou semi-alfabetizados, que necessitam de uma política educacional que os levem de volta à escola e que proporcione os meios necessários para que haja construção do conhecimento. Uma política que favoreça o desenvolvimento das habilidades dessa população que não concluiu até então, as quatro primeiras séries ou que pelo tempo de conclusão e pela rápida escolarização, constituem-se na grande massa dos "analfabetos funcionais".

(...) a estrutura social é obra dos homens e que, se assim for, a sua transformação será também obra dos homens. Isto significa que a sua tarefa fundamental é a de serem sujeitos e não objetos de transformação, tarefa que lhes exige, durante sua ação sobre a realidade, um aprofundamento da sua tomada de consciência da realidade, objeto de atos contraditórios daqueles que pretendem mantê-la como está e dos que pretendem transformá-la. FREIRE (2002, p.48) 
A superação das condições que impedem o acesso à escrita e à leitura é um dos grandes desafios para esse momento histórico, que gera mais pobreza e exclusão social.

Mesmo assim, para que uma educação garanta a qualidade, não basta que se aprenda a decodificação ou que se tenha o comprovante de escolarização. É preciso permitir ao ser humano, avançar em suas necessidades pessoais e profissionais, possibilitando-lhe interpretar, analisar, conhecer, acrescentar, entender e, por fim, participar, interagindo em seu meio social.

[..] os altos índices de evasão e repetência nos programas de educação de jovens e adultos indicam falta de sintonia entre essa escola e os alunos que dela se servem, embora não possamos desconsiderar, a esse respeito, fatores de ordem socioeconômica que acabam por impedir que os alunos se dediquem plenamente a seu projeto pessoal de envolvimento nesse programa. (OLIVEIRA, 2002, p.20)

Além dos fatores que contribuem para a evasão escolar de alunos jovens e adultos, conforme mencionado acima pode-se, acrescentar ainda, a própria linguagem utilizada pela escola, através da qual o professor, assim como toda a equipe escolar, determinam as regras a serem cumpridas. Além disso, aspectos de ordem afetiva também podem contribuir para que esses alunos sejam excluídos mais uma vez.

A Educação de Jovens e Adultos, compreendendo o I Segmento do Ensino Fundamental, deve possibilitar a todos a construção de uma nova história, em igualdade de condições de participação e não simplesmente estar inserido nela. Freire (2000, p. 94) coloca que "onde quer que haja mulheres e homens há sempre o que fazer, há sempre o que ensinar, há sempre o que aprender".

\section{POLÍTICAS EDUCACIONAIS}

No que se refere ao âmbito legal, a Educação de Jovens e Adultos está amparada em diversas políticas nacionais e internacionais.

A Constituição Federal aponta no artigo 205 que a educação é direito de todo cidadão e dever do Estado e da família. Neste mesmo capítulo, no artigo 208, assegura-se a obrigatoriedade do Ensino Fundamental inclusive para aqueles que não o tiveram na idade própria. O artigo 214 aponta como uma das ações do governo, a erradicação do analfabetismo.

No que diz respeito a legislação educacional específica, a Lei de Diretrizes e Bases da Educação Nacional traz um capítulo próprio que trata da EJA, contemplado nos artigos 37 e 38 :

\footnotetext{
Art. 37 $^{\circ}$. A educação de jovens e adultos será destinada àqueles que não tiveram acesso ou continuidade de estudos no ensino fundamental e médio na idade própria.

$\$ \mathbf{1}^{\mathbf{0}}$. Os sistemas de ensino assegurarão gratuitamente aos jovens e aos adultos, que não puderam efetuar os estudos na idade regular, oportunidades educacionais apropriadas, consideradas as características do alunado, seus interesses, condições de vida e de trabalho, mediante cursos e exames.

\$ $\mathbf{2}^{\mathbf{0}}$. O Poder Público viabilizará e estimulará o acesso e a permanência do trabalhador na escola, mediante ações integradas e complementares entre si.

Art. $\mathbf{3 8}^{\circ}$. Os sistemas de ensino manterão cursos e exames supletivos, que compreenderão a base nacional comum do currículo, habilitando ao prosseguimento de estudos em caráter regular.

$\$ \mathbf{1}^{\mathbf{0}}$. Os exames a que se refere este artigo realizar-se-ão:

I - no nível de conclusão do ensino fundamental, para os maiores de quinze anos; II - no nível de conclusão do ensino médio, para os maiores de dezoito anos.

$\S \mathbf{2}^{\mathbf{0}}$. Os conhecimentos e habilidades adquiridos pelos educandos por meios informais serão aferidos e reconhecidos mediante exames.
} 
Ao se tratar do direito a educação e o dever de educar, aponta-se na LBD que: "oferta de educação escolar regular para jovens e adultos, com características e modalidades adequadas às suas necessidades e disponibilidades, garantindo-se aos que forem trabalhadores as condições de acesso e permanência na escola".

Segundo Soares (2002, p. 12)

Ainda que a LDB (9394/96) tenha sido uma colcha de retalhos ao tentar conciliar interesses governistas, privatistas e publicistas, nos arts. 37 e 38 , que dizem respeito diretamente à Educação de Jovens e Adultos, a lei incorporou a mudança conceitual de EJA que se dava desde o final dos anos de 1980. A mudança de "ensino supletivo" para "educação de jovens e adultos" não é uma mera atualização vocabular. Houve um alargamento do conceito ao mudar a expressão de ensino para educação. Enquanto o termo "ensino" se restringe à mera instrução, o termo "educação" é muito mais amplo, compreendendo os diversos processos de formação.

O Parecer 11/2000 regulamenta as Diretrizes Curriculares Nacionais para a EJA e entre outros aspectos estabelece as funções para a EJA: a função reparadora, a medida que resgata um direito negado a uma grande parcela da população; a função equalizadora, evidenciando a necessidade de igualdade de oportunidades dos jovens e adultos ao acesso e permanência na escola; a função qualificadora que prescreve a aprendizagem e atualização contínuas, indo ao encontro do Relatório da Unesco que evidencia uma "educação ao longo do vida" (SOARES, 2002).

Muitas críticas foram feitas as Diretrizes Curriculares Nacionais para a EJA, entre as quais a elaborada por Arroyo (2001) que considera a restrição quanto aos aspectos escolares da EJA, desconsiderando no Brasil, a existência de diversas experiências da educação não formal para adultos.

Outro marco na EJA foi a realização da V CONFINTEA, em Hamburgo, na Alemanha, em 1997, impulsionando posteriormente diferentes iniciativas educativas ligadas a EJA, entre as quais os Encontros Estaduais que objetivaram mapear as ações e instituições envolvidas com a área, além de possibilitar uma aproximação e uma articulação dos segmentos envolvidos com a EJA.

Segundo Romão e Gadotti ( 2007, p.54)

A Declaração de Hamburgo sobre Educação de Adultos estabelece a Educação de Adultos como um direito de todos, destacando a necessidade de diferenciar as necessidades específicas das mulheres, das comunidades indígenas e dos grupos minoritários. A declaração realçou a importância da diversidade cultural e da equidade, dos temas da cultura da paz, da educação para a cidadania e para a democracia, do desenvolvimento sustentável e da transformação da economia.

O objetivo atribuído à EJA pela Declaração de Hamburgo é o desenvolvimento da autonomia e, segundo Di Pierro (2004, p. 12)

[...] o sentido de responsabilidade das pessoas e comunidades para enfrentar as rápidas transformações socioeconômicas e culturais por que passa o mundo atual mediante a difusão de uma cultura de paz e democracia promotora da coexistência tolerante e da participação criativa e consciente dos cidadãos.

Para dar continuidade criou-se o Fórum de Educação de Jovens e Adultos, em diferentes estados e a realização de encontros anuais de educação de jovens e adultos, sendo que "Os fóruns têm sido um espaço de pluralidade e de vitalidade do que acontece na educação de jovens e adultos" (SOARES, 2002, p.9), confirmando assim, a relevância que a modalidade de ensino da EJA tem assumido nas últimas décadas.

Segundo Gustsack (2007, p.102) 
Após a Conferência de Hamburgo, o Brasil aprovou e implementou planos e programas de alfabetização, elevação de escolaridade, qualificação profissional, sáude preventiva, educação ambiental, educação em direitos humanos, educação na reforma agrária. Essas iniciativas, no entanto, careceram de articulação dispersando os recursos já escassos, além de limitar o impacto social dos programas e principalmente sem que " se tenha logrado articular minimamente tais iniciativas em favor de uma aprendizagem integral das pessoas jovens e adultas" (Di Pierro, 2004, p. 15).

Ainda em referência às políticas destinadas para tal modalidade, o Plano Nacional de Educação (LEI 10.172/01) que encerra-se no primeiro decênio deste século, apontou objetivos e metas. Foi elaborado e está em processo de aprovação o novo plano (2011 2020), que apresenta metas e estratégias específicas para a EJA.

Entre as diretrizes estabelecidas no novo plano, que contemplam a EJA, destacamse: erradicação do analfabetismo; universalização do atendimento escolar; superação das desigualdades educacionais.

Dentre as metas e estratégias, evidenciam-se: o fomento de programas de EJA para população urbana e do campo; a oferta gratuita e continuidade da EJA para todos aqueles que não tiveram acesso na idade própria; disponibilidade de no mínimo, $25 \%$ das matrículas de educação de jovens e adultos na forma integrada à educação profissional nos anos finais do ensino fundamental e no ensino médio.

"A meta estipulada em Hamburgo é de reduzir em 50\% o analfabetismo e a meta do Plano Nacional de educação é a de superar o analfabetismo até 2011" (GUSTSACK, 2007, p. 103). Infelizmente as metas ainda não foram atingidas e para serem precisa de um financiamento substancial na educação e em especial na EJA.

A VI CONFINTEA foi realizada em 2009, em Belém do Pará, reforçando a importância da aprendizagem e da educação de adultos para uma sociedade viável, enaltecendo a aprendizagem ao longo da vida como fundamental. Reafirmou também os quatro pilares da educação: aprender a ser, aprender a saber, aprender a fazer e , aprender a viver junto.

A educação enquanto direito está condicionada as intenções políticas, participação, financiamentos, inclusão, equidade e qualidade. Nestas diferentes esferas, no documento final, são expressos compromissos, ações e sugestões para o incremento desta modalidade de ensino.

As Conferências que tratam da EJA já fazem história no mundo da educação. Há ... um reconhecimento por parte da sociedade mundial e dos organismos internacionais da importância da EJA para o fortalecimento da cidadania, para a formação cultural da população e para a melhoria do bem-estar da sociedade. Se, por um lado, esse reconhecimento formal reflete conquistas das lutas de educadores e entidades, por outro, há uma grande contradição entre esse reconhecimento formal e as ações do governo. Algumas contradições foram apontadas por Haddad quando analisou a Declaração de Hamburgo e o Plano de Ação para o Futuro, documentos originários da V CONFINTEA. Se por um lado as conferências representam avanços, por outro não fazem uma análise conjuntural sobre as consequências sociais do sistema capitalista, da globalização da economia e do impacto social do crescente desemprego que afeta milhares de cidadãos (GUTSACK, 2007, p. 101).

A falta de definição da identidade da EJA também é questão que merece reflexão. Se por um lado pode ser considerada enquanto uma modalidade de ensino, por outro lado pode ser entendida como um espaço de atuação que extrapola a escola, sendo constituída por diferentes práticas educativas. 


\section{DISCENTES DA EJA EM PONTA GROSSA}

Para se estabelecer o perfil dos discentes da EJA em Ponta Grossa foram aplicados 209 questionários para alunos de 35 escolas.

Com relação a faixa etária, percebeu-se o predomínio de alunos com mais de 41 anos, 102 pessoas (49\%), seguido da faixa etária de 25 a 30 anos e 36 a 40 anos, com 25 alunos em cada faixa (12\%). Nas faixas etárias de 31 a 35 anos, 24 alunos (11\%) e de 15 a 19 anos (10\%). A faixa etária que teve menos alunos foi de 20 a 24 anos, com 13 alunos (6\%). Os dados podem ser visualizados na tabela e gráfico abaixo.

Embora existam pesquisas que detectam um decréscimo na faixa etária de alunos na modalidade da EJA, nesta pesquisa essa tendência não se confirma, sendo predominada por alunos mais velhos.

Tabela 1 : Faixa Etária

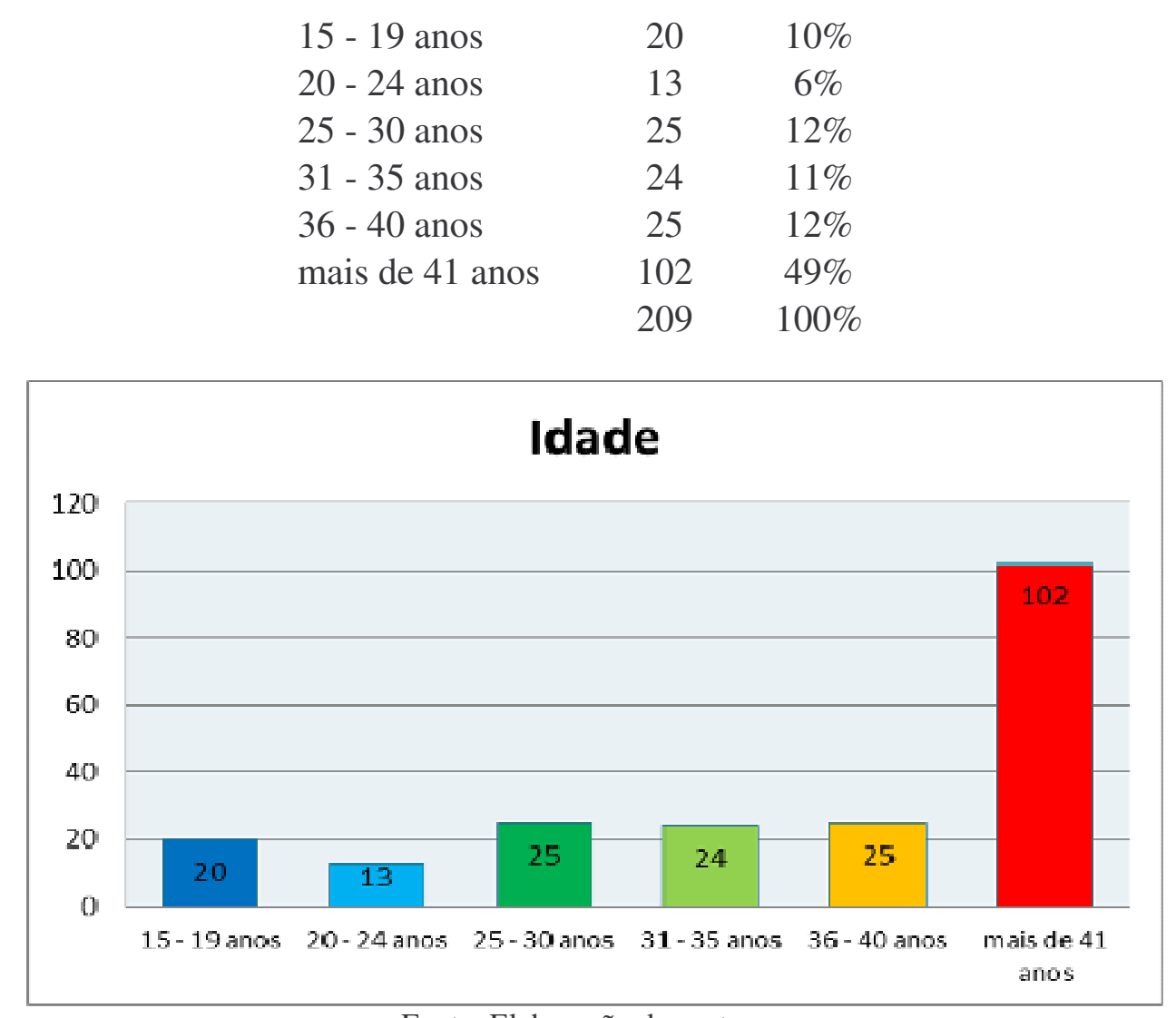

Fonte: Elaboração das autoras.

Com relação ao gênero, predominou o feminino com 145 alunas (69\%) e 64 alunos $(31 \%)$, conforme tabela e gráfico a seguir.

Tabela 2: Gênero

$\begin{array}{lcc}\text { Feminino } & 145 & 69 \% \\ \text { Masculino } & 64 & 31 \% \\ & 209 & 100 \%\end{array}$




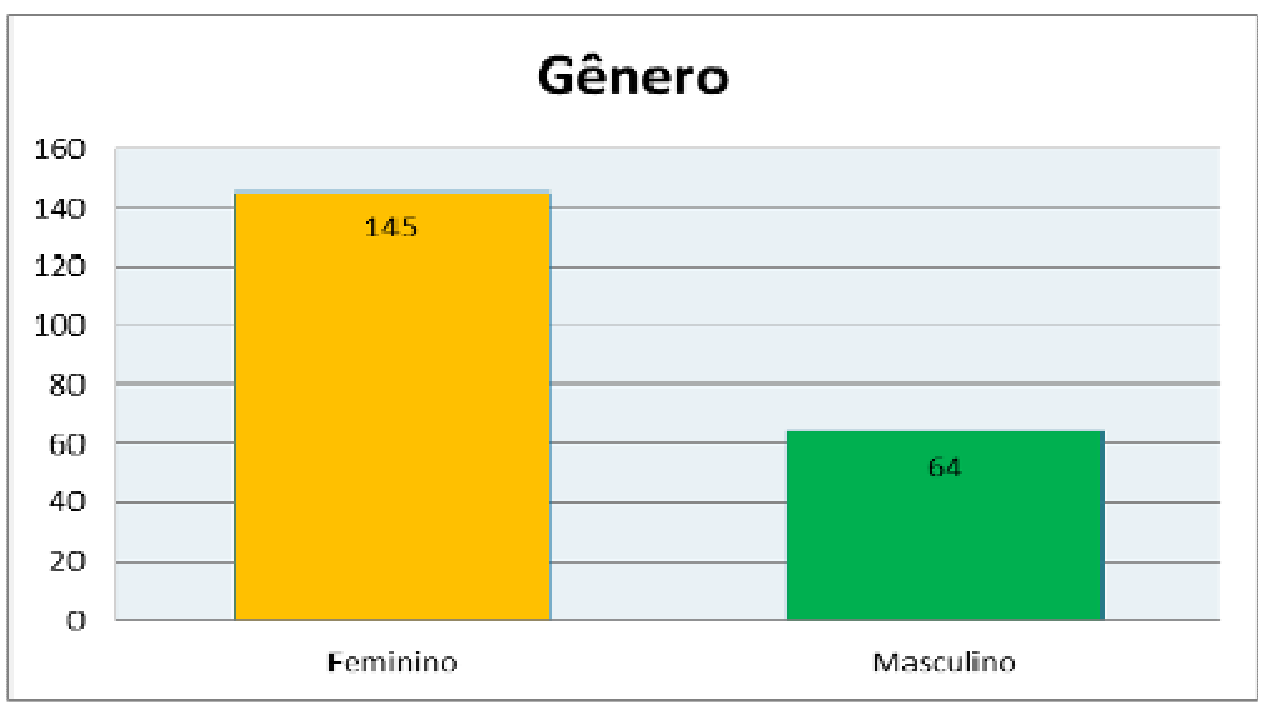

Fonte: elaboração das autoras.

Com relação ao estado civil, 73 (35\%) são casados, seguidos de 56 (27\%) são solteiros e 33 (16\%) moram com companheiro, Em menor número estão 19 viúvos (9\%), 18 separados (9\%) e 10 (5\%) são divorciados.

Tabela 3: Estado Civil

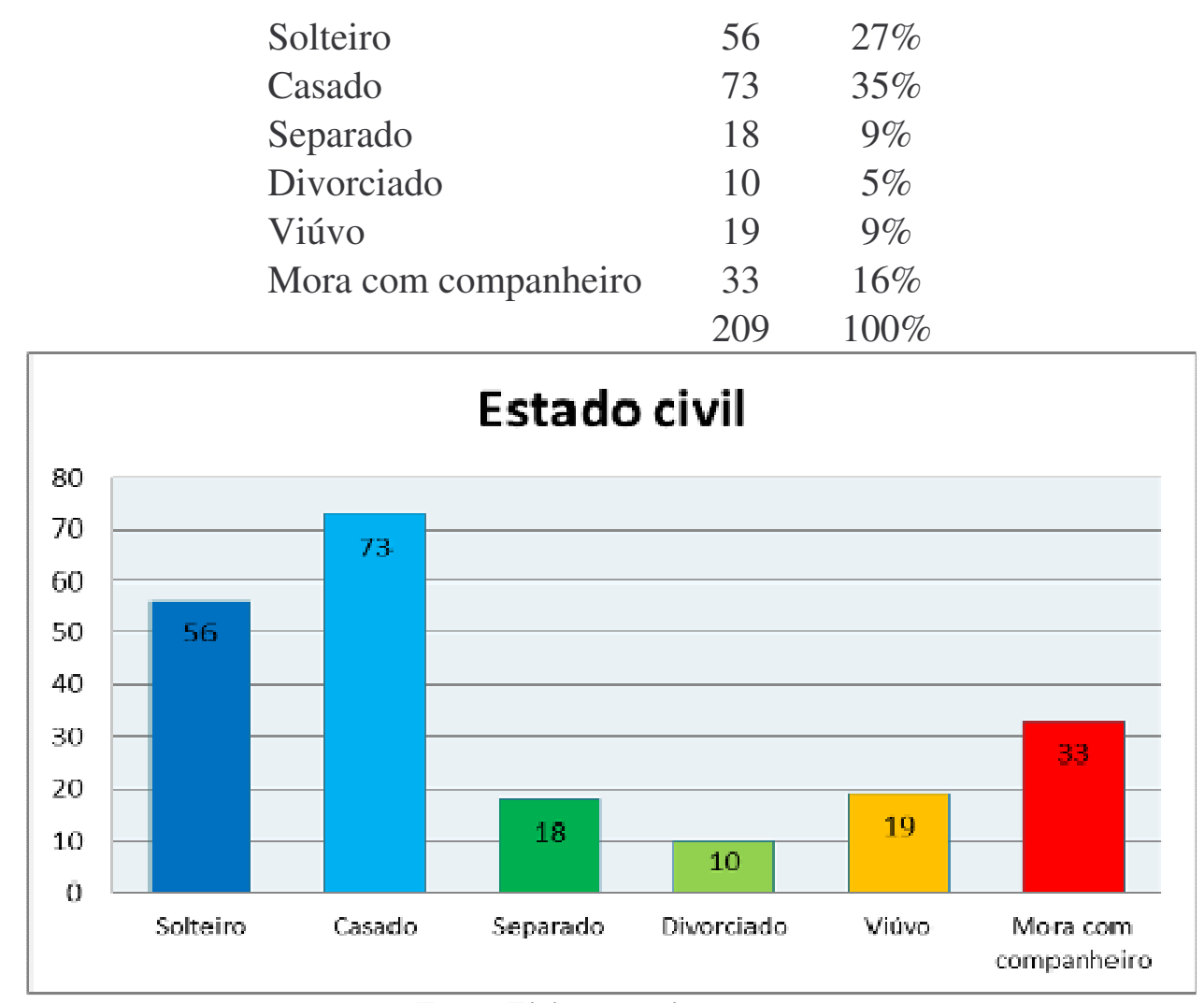

Fonte: Elaboração das autoras 
A grande maioria dos alunos 53 (25\%) não possuem filhos, e dos que possuem filhos predominou 2 filhos com $38(18 \%)$ e 3 filhos com $34(16 \%)$.

Tabela 4: Número de Filhos

$\begin{array}{lcc}\text { Não } & 53 & 25 \% \\ 1 \text { filho } & 28 & 13 \% \\ 2 \text { filhos } & 38 & 18 \% \\ 3 \text { filhos } & 34 & 16 \% \\ 4 \text { filhos } & 19 & 9 \% \\ 5 \text { ou mais filhos } & 37 & 18 \% \\ & 209 & 100 \%\end{array}$

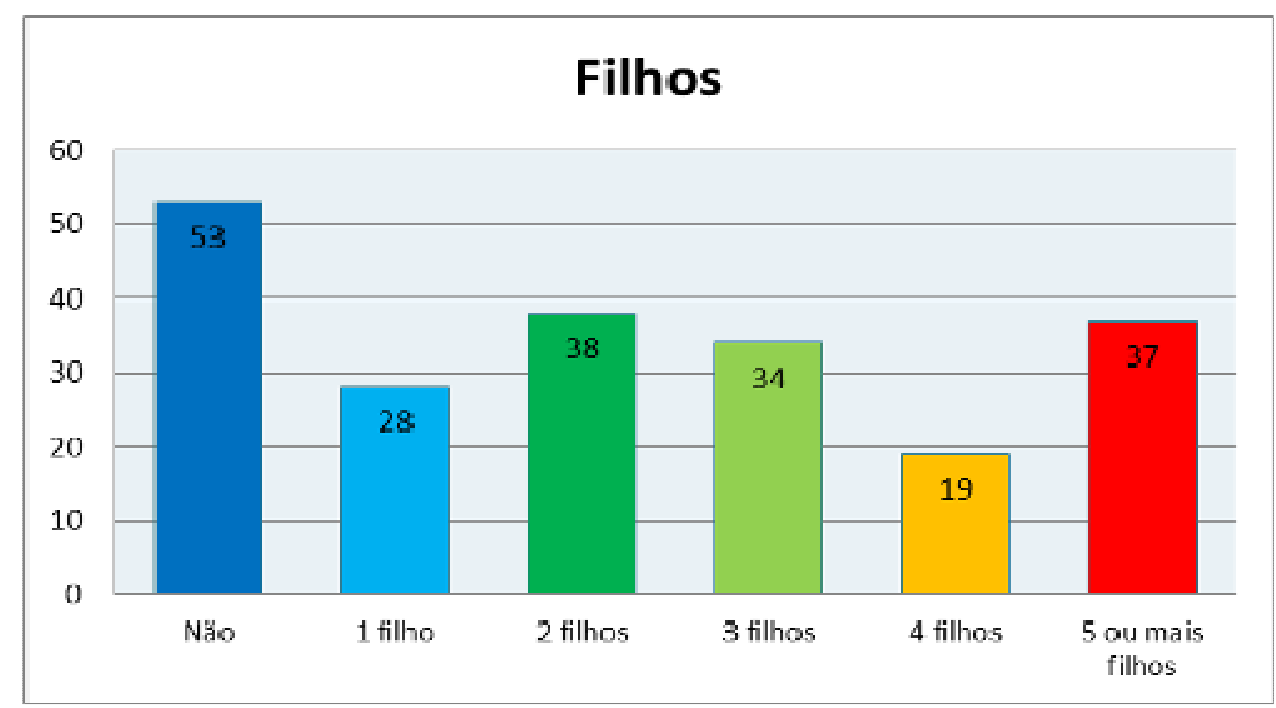

Fonte: Elaboração das autoras

Com relação a ocupação, ao alunos apresentaram inúmeras atividades, predominando a dona de casa, doméstica e diarista. Um grande número também encontra-se sem atividade laboral, conforme tabela e gráfico abaixo.

Tabela 5: Ocupação

$\begin{array}{lrr}\text { Açougueiro } & 2 & 1 \% \\ \text { Ajudante } & 2 & 1 \% \\ \text { Aposentado } & 9 & 4 \% \\ \text { Armador } & 1 & 0,5 \% \\ \text { Atendente } & 2 & 1 \% \\ \text { Autônomo } & 2 & 1 \% \\ \text { Auxiliar de cozinha } & 3 & 1 \% \\ \text { Auxiliar de produção } & 3 & 1 \% \\ \text { Auxiliar operacional } & 1 & 0,5 \%\end{array}$


Auxiliar de serviços gerais

$84 \%$

Babá

$2 \quad 1 \%$

Borracheiro

$2 \quad 1 \%$

Cabeleireiro

$1 \quad 0,5 \%$

Caldeireiro

$10,5 \%$

Carpinteiro

$10,5 \%$

Carpir (lotes, terrenos)

$10,5 \%$

Copeira

$1 \quad 0,5 \%$

Costureira

$3 \quad 1 \%$

Cozinheiro

Cuidador de idoso

$10,5 \%$

Diarista

$2 \quad 1 \%$

Doméstica

$13 \quad 6 \%$

Dona de casa

$18 \quad 9 \%$

$39 \quad 19 \%$

Frentista

Gerente de vendas

$10,5 \%$

$1 \quad 0,5 \%$

Mecânico

$2 \quad 1 \%$

Mecânico bombista

Metalúrgico

$1 \quad 0,5 \%$

$2 \quad 1 \%$

Motorista

$1 \quad 0,5 \%$

Operador de máquina

$10,5 \%$

Pensionista

$2 \%$

Pintor

Salgadeira

Sem ocupação

Serralheiro

Servente

Servente de pedreiro

$5 \quad 2 \%$

$10,5 \%$

$1 \quad 0,5 \%$

$53 \quad 25 \%$

$1 \quad 0,5 \%$

$4 \quad 2 \%$

$1 \quad 0,5 \%$

Vendedor

$10 \quad 5 \%$

Vidraceiro

$1 \quad 0,5 \%$

Vigia

$2 \quad 1 \%$

Zelador

$31 \%$

$209 \quad 100 \%$ 


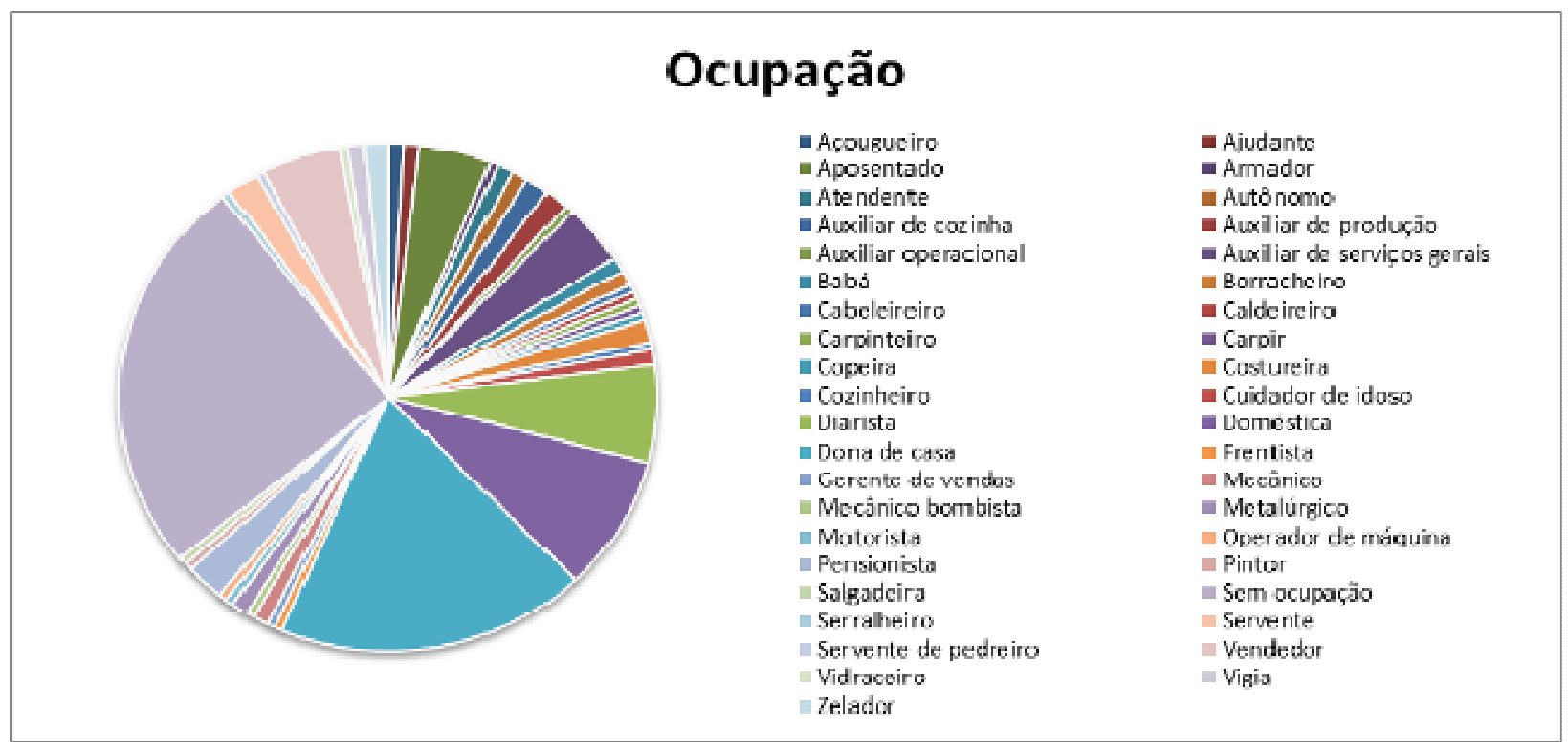

Fonte: Elaboração das autoras

Complementando a essa pergunta, 102 alunos (49\%) não trabalham (aposentados, pensionistas, donas de casa e casos de trabalho temporário), sendo que aqueles que possuem uma atividade laboral, $47(22 \%)$ trabalham no mercado informal e 42 (20\%) no mercado formal e 17 (8\%) são autônomos.

Tabela 6: Trabalho

$\begin{array}{lcc}\text { Formal } & 42 & 20 \% \\ \text { Informal } & 47 & 22 \% \\ \text { Autônomo } & 17 & 8 \% \\ \text { Voluntário } & 1 & 0 \% \\ \text { Não trabalha } & 102 & 49 \% \\ & 209 & 100 \%\end{array}$

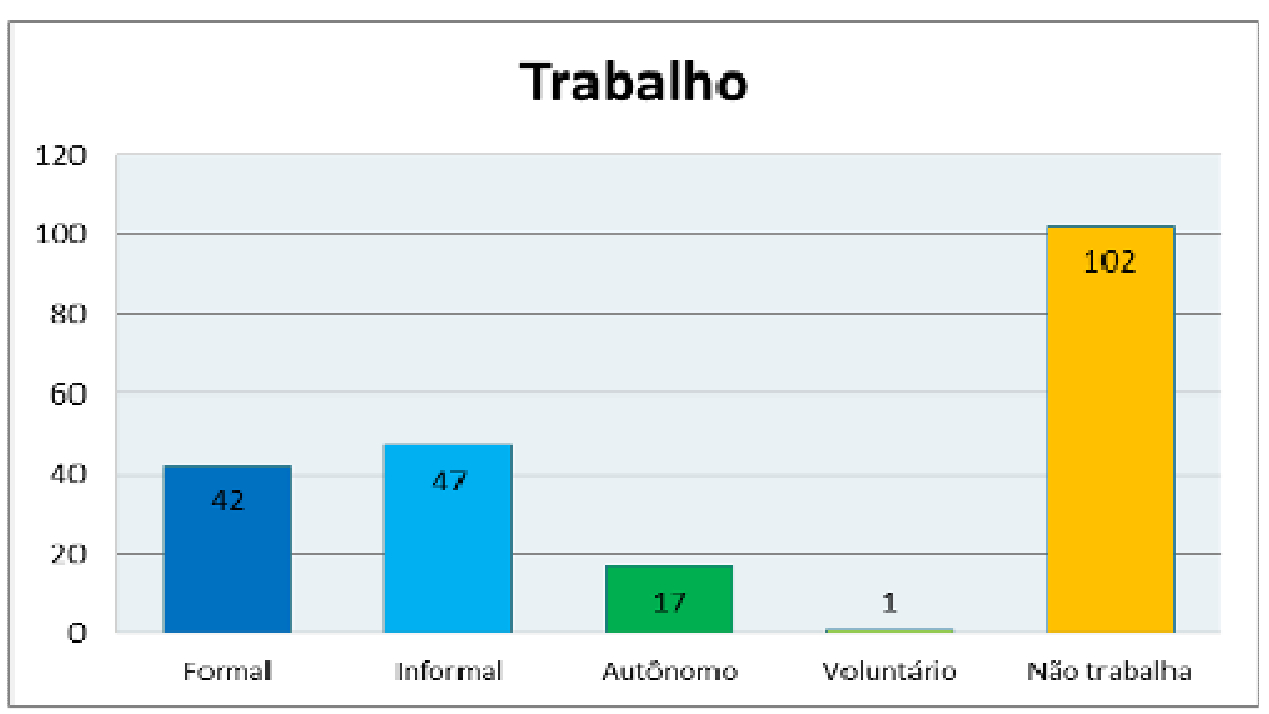

Fonte: Elaboração das autoras 
Referente a renda, ficou equilibrada, sendo que 86 alunos (22\%) recebem até 1 salário mínimo e 79 (20\%) recebem de 1 a 2 salários. Em menor número 29 alunos (8\%) recebem de 2 a 3 salários mínimo. Os dados podem ser vistos na tabela e gráfico abaixo.

TABELA 7: Renda familiar

$\begin{array}{lcc}\text { Até 1 SM } & 86 & 22 \% \\ \text { De 1 a 2 SM } & 79 & 20 \% \\ \text { De 2 a 3 SM } & 29 & 8 \% \\ \text { De 3 a 4 SM } & 9 & 0,5 \% \\ \text { Mais de 4 SM } & 4 & 49 \% \\ \text { Sem renda } & 2 & 1 \% \\ & 209 & 100 \%\end{array}$

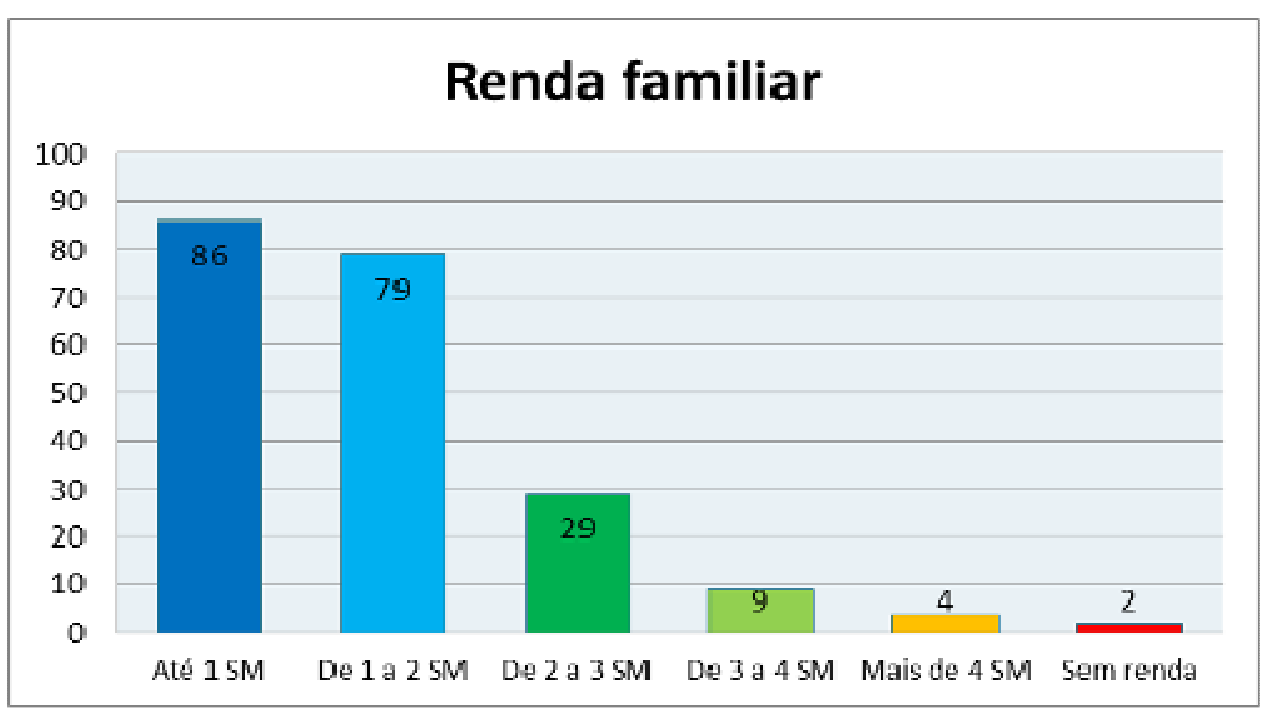

Fonte: Elaboração das autoras

Os alunos também foram questionados com relação ao tempo que pararam de estudar. O que mais chamou a atenção foi o número de alunos que há mais de 20 anos deixaram de estudar sem ter o Ensino Fundamental (67 alunos, 32\%) e os que nunca estudaram ( 51 alunos, 24\%).

Tabela 8: Período fora da escola

$\begin{array}{lrr}\text { Nunca parou de estudar } & 8 & 4 \% \\ 1 \text { ano } & 20 & 10 \% \\ 2 \text { anos } & 6 & 3 \% \\ 3 \text { anos } & 4 & 2 \% \\ 4 \text { anos } & 3 & 2 \% \\ 5 \text { anos } & 15 & 7 \% \\ 6-10 \text { anos } & 16 & 8 \% \\ 11-15 \text { anos } & 11 & 5 \% \\ 16-20 \text { anos } & 8 & 4 \%\end{array}$




$\begin{array}{lrr}\text { mais de } 20 \text { anos } & 67 & 32 \% \\ \text { Nunca estudou } & 51 & 24 \% \\ & 209 & 100 \%\end{array}$

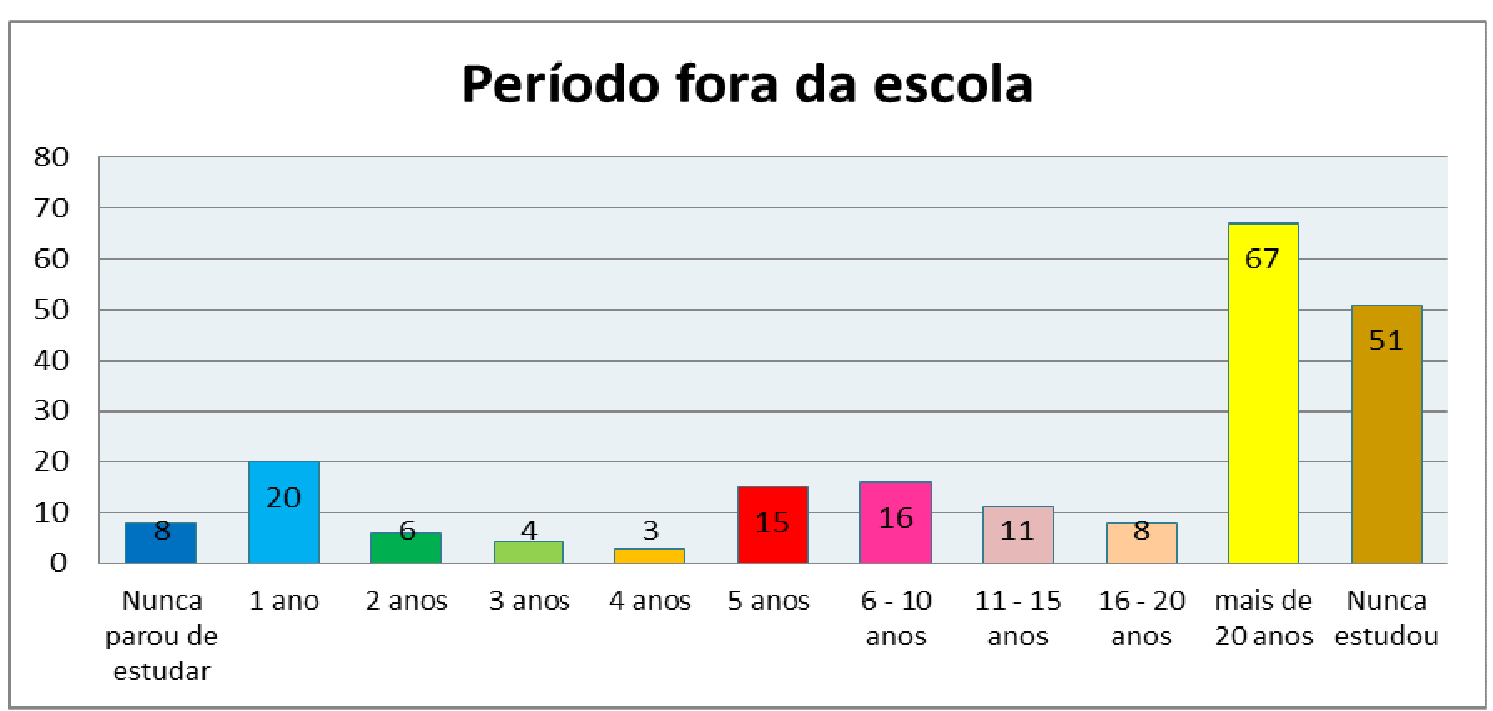

Fonte: Elaboração das autoras

Os alunos apresentaram quais os motivos que os levaram a ingressar na EJA. As respostas variaram, sendo que o motivo apresentado pelo maior número foi aprender mais respondido por 66 (32\%), seguido de aprender ler e escrever apontado por 48 (23\%), para conseguir um trabalho ou ascender na carreira indicada por 39 (19\%) e manifestaram a importância da escolarização $32(15 \%)$, A elevação ou resgate da auto estima e a qualidade de vida foram indicadas por $16(8 \%)$ e $8(4 \%)$ respectivamente.

Tabela 9: Motivos para ingressar na EJA

Trabalho

Aprender a ler e escrever

Importância da escolarização

Aprender mais

Qualidade

Auto-estima

$\begin{array}{rr}39 & 19 \% \\ 48 & 23 \% \\ 32 & 15 \% \\ 66 & 32 \% \\ 8 & 4 \% \\ 16 & 8 \% \\ 209 & 100 \%\end{array}$




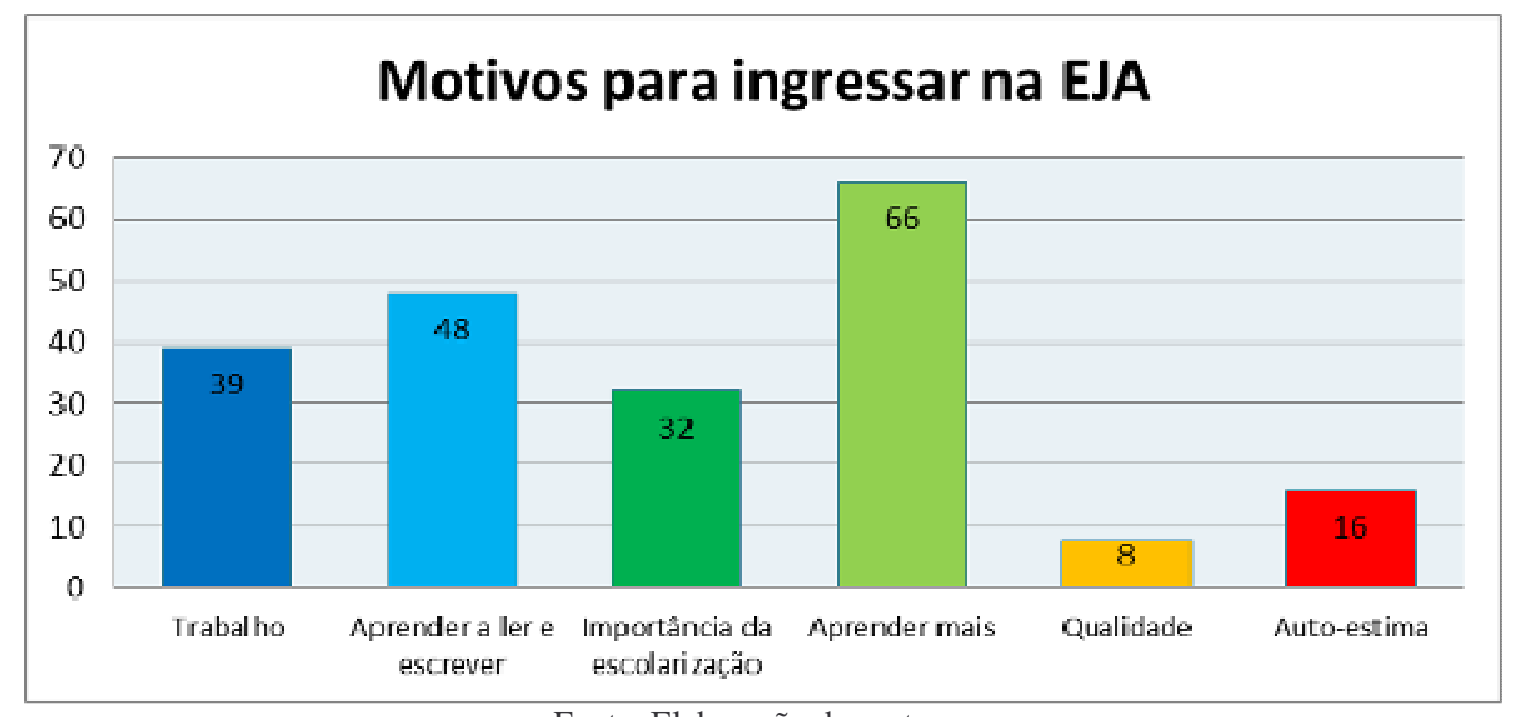

Fonte: Elaboração das autoras

Referente as expectativas que os alunos tem com relação a EJA, notou-se que a maioria dos que responderam aos questionários, 65 alunos (31\%) buscam mais aprendizagem, seguidos de 52 (25\%) para conseguirem emprego ou melhorarem profissionalmente e $32(15 \%)$ buscam pela maior escolaridade uma vida melhor. Os dados podem ser visualizados na tabela e gráficos abaixo.

Tabela 10: Expectativas

$\begin{array}{lcc}\text { Estudo } & 14 & 7 \% \\ \text { Aprendizagem } & 65 & 31 \% \\ \text { Emprego } & 52 & 25 \% \\ \text { Vida melhor } & 32 & 15 \% \\ \text { Cidadania } & 9 & 4 \% \\ \text { Autonomia } & 13 & 6 \% \\ \text { Ensinar filhos e netos } & 5 & 2 \% \\ \text { Pegar ônibus } & 6 & 3 \% \\ \text { Concretização de sonhos } & 13 & 6 \% \\ & 209 & 100 \%\end{array}$




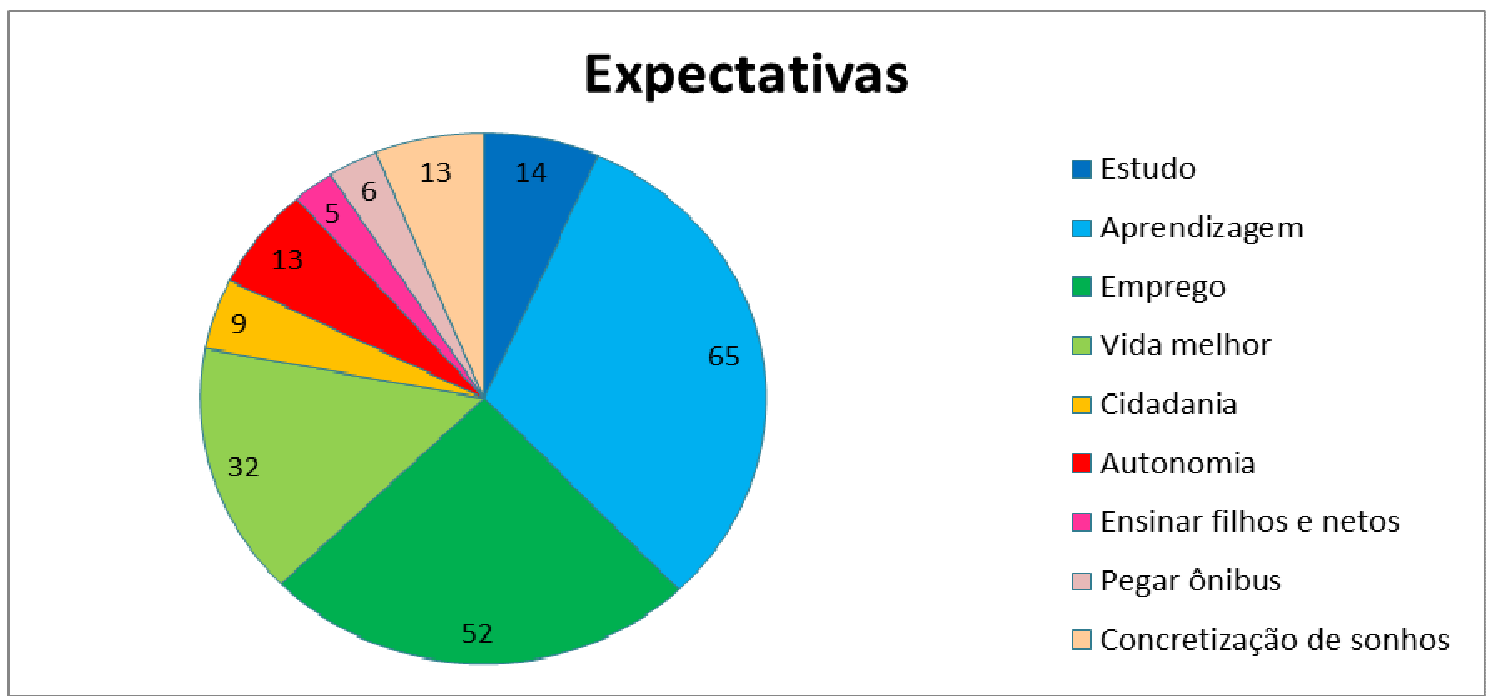

Fonte: Elaboração das autoras

\section{PARA CONCLUIR...}

Apesar da importância que a EJA tem conquistado nas últimas décadas ainda apresenta-se com sentido utilitarista, produtivista e compensatório e aos poucos evidencia a emancipação do jovem e do adulto, mas ainda recebe recursos insuficientes para a concretização das metas estabelecidas, em especial, para a erradicação do analfabetismo no Brasil, ainda distante.

Outro ponto frágil nas políticas da EJA refere-se ao reconhecimento como direito de todo cidadão, entretanto, pouco são implementadas os espaços e estratégias para atender esse direito e como decorrência os trabalhadores não são beneficiados.

A educação de jovens e adultos é relacionada a projetos de desenvolvimento econômico brasileiro. Dessa forma, o processo de significação está alicerçado na ideologia compensatória e sua ênfase na educação como capital que promove o desenvolvimento. A Educação de jovens e Adultos é, portanto, compensatória, supletiva e tem função adaptativa (GUSTSACK, 2007, p. 99).

As parcerias com empresas e demais instituições da sociedade civil para possibilitar que as metas traçadas para a EJA sejam atingidas, podem ser positivas, mas de forma alguma podem diminuir o compromisso do Estado com essa parcela da população, que reivindica o cumprimento de seus direitos, em especial, com relação à educação.

A Política educacional constitui um aspecto específico da Política social. Considerando em especial a política para a modalidade da EJA, segundo Gustsack (2207, p. 97)

[...] não existe atualmente, no Brasil, políticas públicas para a educação de jovens e adultos. O que existe são tentativas de dar a impressão de que o governo federal e os governos estaduais estão se preocupando com o problema através de propagandas e da conclamação à sociedade civil organizada.

O aluno da EJA na cidade de Ponta Grossa, apresenta um perfil com predominância da faixa etária acima dos 41 anos, do sexo feminino, casados, com renda de até 1 salário mínimo, com 20 anos ou mais fora da escola e manisfestam muitas expectativas na escolaridade, em especial para melhorar ou adquirir emprego ou mesmo conseguir melhores condições de vida.

De certa maneira pode-se concluir que a escolaridade tem estreita ligação com a questão econômica e ainda um número significativo de indivíduos não são alfabetizados ou 
são analfabetos funcionais. A EJA representa para muitos brasileiros as expectativas de melhoria de vida e da conquista de um direito - a educação - prescrito na Constituição para garantir o exercício pleno da cidadania.

Assim, o Brasil precisa instituir, planejar e realmente efetivar uma política educacional para esta população que por diferentes motivos ficaram à margem e hoje colhem as consequências de uma falta de escolaridade mínima para uma vida com mais autonomia e dignidade.

\section{REFERÊNCIAS}

BRASIL. Constituição da República Federativa do Brasil: promulgada em 5 de outubro de 1988. 36. ed. São Paulo: Saraiva, 2005.

Lei 9394 de 20 de dezembro de 1996. Dispõe sobre as Diretrizes e Bases da Educação Nacional. Brasília: MEC, 1996.

Lei 10172 de 9 de janeiro de 2001. Dispõe sobre o Plano Nacional de Educação. Brasília: MEC, 2001.

DI PIERRO, M.C. Um balanço da evolução da educação de jovens e adultos no Brasil. In: Alfabetização e cidadania. Revista de educação de Jovens e Adultos, n.17, maio de 2004, p.11-22.

FREIRE, P. Pedagogia da autonomia: saberes necessários à prática educativa. 23 ed. Rio de Janeiro: Paz e Terra, 2000.

FREIRE, P. Educação e mudança. 26º ed.; Rio de Janeiro: Paz e Terra, 2002.

GUSTSACK, F; VIEGAS, M; BARCELOS, V. Educação de jovens e adultos: saberes e fazeres. Santa Cruz do Sul: EDUNISC, 2007.

OLIVEIRA, M. K. Jovens e Adultos como sujeitos de conhecimento e aprendizagem. In RIBEIRO, V. M. Educação de Jovens e Adultos novos leitores, novas leituras. São Paulo: Editora Mercado de Letras, 2002.

ROMÃO, J.E.; GADOTTI, M. Educação de Adultos: cenários, perspectivas e formação de educadores. Brasília: Liber, 2007.

SOARES, L. Educação de jovens e adultos. Rio de janeiro: DP\&A, 2002.

UNESCO. Conferência mundial sobre a educação de adultos. Declaração de Hamburgo. Nova York: Unesco, 1999.

Notas:

\footnotetext{
${ }^{1}$ Texto apresentado no 25 Simpósio Brasileiro de Política e Administração da Educação (ANPAE) - 2011

${ }^{2}$ Pedagoga, Doutora em Educação. Professora Permanente dos Programas de Mestrado e de Doutorado em Educação na UEPG. Pesquisadora Produtividade pelo CNPq. E-mail: soliveira13@uol.com.br
}

Recebido em 23/02/2011

Aprovado em 30/03/2011 